\title{
Administration of assessment instruments during the first rehabilitation of patients with spinal cord injury: a retrospective chart analysis
}

\author{
Patricia Lampart ${ }^{1,2} \cdot$ Armin Gemperli $^{2,3} \cdot$ Michael Baumberger ${ }^{1} \cdot$ Ines Bersch $^{1} \cdot$ Birgit Prodinger $^{2,3} \cdot$ Klaus Schmitt $^{1} \cdot$ \\ Anke Scheel-Sailer $\mathbb{D}^{1,2}$
}

Received: 23 June 2017 / Revised: 26 October 2017 / Accepted: 12 November 2017 / Published online: 20 December 2017

(c) International Spinal Cord Society 2017

\begin{abstract}
Study design Retrospective chart analysis.

Objectives To examine which professionals administered which assessment instruments in which patient in clinical practice during first rehabilitation after newly acquired spinal cord injury (SCI) and the differences in the frequencies of different assessments between patient groups.

Setting Specialized SCI acute care and rehabilitation clinic.

Methods Patients after SCI, aged 18 years and above, admitted for first rehabilitation between December 2014 and December 2015 were analyzed. Descriptive statistics of 54 selected assessments. $p$ values based on the $\chi^{2}$ test were calculated for assessments used in both paraplegic and tetraplegic patients.

Results One hundred and nineteen patients were screened. Forty-one assessments were administered, of which 10 on average more than once per patient. The most frequently used assessments were Spinal Cord Independence Measure III (7.7 times per patient), Skin Assessment (3.6 times), and Manual Muscle Test (3.2 times for Lower Extremities; 2.5 times for Upper Extremities). The American Spinal Injury Association Impairment Scale was administered on average 1.9 times per patient. More variation in the number of assessments per patient was observed in patients with complete and incomplete lesions compared to patients with paraplegia and tetraplegia.

Conclusion Assessments covering neurological functioning, mobility, and self-care are used in clinical practice during first rehabilitation of patients with SCI, while others covering autonomic functioning, pain, participation, or quality of life are still missing. Based on these observations and national and international requirements, a meaningful standard for an assessment toolkit, applicable in general and in specific subgroups, needs to be defined and implemented.
\end{abstract}

\section{Introduction}

Assessments are an essential part of rehabilitation management at a micro-level. However, they are also embedded

Electronic supplementary material The online version of this article (https://doi.org/10.1038/s41393-017-0039-x) contains supplementary material, which is available to authorized users.

Anke Scheel-Sailer

anke.scheel@paraplegie.ch

1 Swiss Paraplegic Centre (SPC), Nottwil, Switzerland

2 Department of Health Sciences and Health Policy, University of Lucerne, Lucerne, Switzerland

3 Swiss Paraplegic Research (SPF), Nottwil, Switzerland in a wider framework that comprises quality management programs at the meso-level and national reporting at the macro-level [1-3]. National reporting requires harmonized data collection according to a widely accepted framework that includes, for example, internationally accepted classifications such as the International Classification of Diseases (ICD) or the International Classification of Functioning, Disability, and Health (ICF) [4-6]. These classifications can be considered to make up a unifying model that determines "what to measure" [6-8].

The living conditions and functional capacity of a person affected by a spinal cord injury (SCI) depend on the level of body structure and function, activity, and participation, as well as personal and contextual factors [9]. In order to examine these components in a comparable and defined way, certain assessments are used as part of 
clinical management [10]. In the first step of the RehabCycle $^{\circledR}$ [11], the needs to be addressed are assessed by describing specific parts of a person's functioning, and the goal-setting process is shaped [12]. Repeating these assessments after the administration of an intervention helps identify the changes and outcomes of rehabilitative interventions [1, 11, 13, 14]. Appropriate assessment standards can indicate the effectiveness of therapeutic interventions and, therefore, they can be used to identify the best practice models and to determine the quality of rehabilitation benchmarks [10, 15].

The standardization of assessments used as outcome measures allows for national and international reporting [15, 16] as well as comparison between different rehabilitation programs [17]. For clinical management, assessments should be specific and meaningful $[1,10,12]$ and tested for their psychometric quality $[3,15]$. A number of initiatives have been undertaken to integrate different disease characteristics into relevant clinical outcome measures $[3,7,18]$, such as the development of the International SCI Data Set (ISCoS) [19]. Further, cohort studies such as the SwiSCI study [20, 21] were set up to provide practitioners with tools that allow the merging of clinical management and scientific evaluation. Additionally, first rehabilitation toolkits based on the consensus of various organizations have now been published to harmonize data collection for SCI outcome measures at a national and worldwide level [3]. These toolkits include relevant topics related to the data to be recorded for each patient and the assessments that have to be performed [3].

Despite these developments and international recommendations, there are no standard assessments that are routinely used in clinical practice. One further step for developing a clinically and scientifically accepted standard toolkit is to examine the use of assessments in the natural work environment. Therefore, the aim of this study was to get an overview of the currently used assessment instruments at the Swiss Paraplegic Centre (SPC) during the first rehabilitation intervention in patients with newly acquired SCI. The following questions were addressed: which group of professionals administered which assessment instruments in clinical practice, and in whom (patient groups) and how often were the instruments administered at this specialized clinic. Furthermore, significant differences in the number of assessments per patient between patient groups were also examined.

\section{Methods}

\section{Research design}

Within the framework of a quality assurance project, a retrospective chart review was performed. The Ethics Commission Northwest and Central Switzerland approved of this study (EKNZ UBE-15/109) and all the institutional regulations were followed.

\section{Patients and setting}

The study included patients with a newly acquired traumatic or non-traumatic SCI or SCI comparable syndromes who were admitted for their first rehabilitation intervention to a specialized acute care and rehabilitation clinic for SCI between December 2013 and December 2014. Patients under the age of 18 years and those who did not provide their consent for the use of their data for retrospective data analyses were excluded.

The center has been a part of the SwiSCI pathway 3 study (Swiss Spinal Cord Injury Cohort Study) [22] since May 2013 and the EMSCI study (European Multicenter Study about Spinal Cord Injury 2016) [23] since August 2012, and conducts the specifically recommended assessments for patients participating in these studies. Furthermore, the National Association for Quality Development in Clinics (ANQ) mandates the selection of participation goals in every patient and the monthly reporting of the Spinal Cord Independence Measurement III (SCIM III) [24]. The monthly SCIM III is therefore part of an administered control system. In 2012, physiotherapists (PTs) and occupational therapists (OTs) developed recommendations for an assessment schedule that outlines the type of assessment and their timeframes for administration. All the selected assessments were psychometrically tested and recommended by international SCI societies. Additionally, other assessments can be initiated by the therapists or requested by physicians in cases where there are clinical indications for the same.

\section{Data collection}

First, the quality control department selected patients according to the ICD codes [25], if they met the inclusion criteria. The generated list of variables was as follows: sex, age at admission, length of stay, cause of SCI, and completeness of lesion. Next, a list of assessments to be screened was created, based on SwiSCI, EMSCI, and a clinic intern recommendation list (see section Patients and setting) (Table 1: Assessment Instruments). Furthermore, specialists (nurses, therapists, and physicians) were consulted to add relevant assessments and examinations. Because many nurse assessments were neither validated nor standardized, this routinely performed structured documentation was not listed.

The patient records consist of paper and electronic documentations. Four electronic databases were used in parallel with different purposes: Medfolio (Nexus, Switzerland), WicareDoc, 4.2.0 (Wigasoft, Switzerland), Patient 
Table 1 Abbreviation and full name of all screened assessments during first rehabilitation of patients with spinal cord injury, responsible profession, and places of documentation

\begin{tabular}{|c|c|c|c|}
\hline & Abbreviation & Full name & $\begin{array}{l}\text { Documentation place } \\
\text { Profession }\end{array}$ \\
\hline 1 & AIS & $\begin{array}{l}\text { American Spinal Injury Association (ASIA) } \\
\text { Impairment Scale }\end{array}$ & Medfolio* \\
\hline 2 & MMI & Multimorbidity Index & Medfolio* \\
\hline 3 & - & Urodynamics & Medfolio* \\
\hline 4 & - & X-ray Spine & PACS* \\
\hline 5 & CT Spine & Computed Tomography Spine & PACS* \\
\hline 6 & MRI Spine & Magnetic Resonance Imaging Spine & PACS* \\
\hline 7 & - & Osteoporosis Diagnostics & PACS $*$ \\
\hline 8 & PFT & Pulmonary Function Test & Medfolio* \\
\hline 9 & - & Performance Test & Medfolio* \\
\hline 10 & $\mathrm{SEP}+\mathrm{ENG}$ Tibialis & $\begin{array}{l}\text { Sensible Evoked Potentials } \\
\text { +Elektroneurografie Tibialis }\end{array}$ & Medfolio* \\
\hline 11 & PAP & Peripheral Activated Potentials & Medfolio* \\
\hline [12] & $\mathrm{SEP}+\mathrm{ENG}$ Ulnaris & $\begin{array}{l}\text { Sensible Evoked Potentials } \\
\text { +Elektroneurografie Ulnaris }\end{array}$ & Medfolio* \\
\hline [13] & Phrenicus-ENG & Phrenicus-Elektroneurografie & Medfolio* \\
\hline [14] & TTT & Tilt Table Test & Medfolio* \\
\hline 15 & - & Neuropsychological Examination & Medfolio \\
\hline 16 & SCIM III & Spinal Cord Independence Measure III & Medfolio $^{\circ,+, \#}$ \\
\hline 17 & MMT LE & Manual Muscle Test Lower Extremities & WicareDoc $^{\circ}$ \\
\hline [18] & ROM UE & Range Of Motion Upper Extremities & WicareDoc $^{\circ}$ \\
\hline 19 & ROM LE & Range Of Motion Lower Extremities & WicareDoc $^{\circ}$ \\
\hline 20 & WISCI II & Walking Index for Spinal Cord Injury II & WicareDoc $^{\circ}$ \\
\hline [21] & - & $\begin{array}{l}\text { Diagnostics Breathing Therapy according to } \\
\text { ICF, SPC }\end{array}$ & WicareDoc $^{\circ}$ \\
\hline [22] & AMW & Activity Test for Mobility in Wheelchair & WicareDoc $^{\circ}$ \\
\hline [23] & - & Diagnostics Shoulder Examination, SPC & Paper, WicareDoc $^{\circ}$ \\
\hline [24] & WUSPI & Wheelchair User's Shoulder Pain Index & WicareDoc $^{\circ}$ \\
\hline 25 & AS & Ashworth Scale & WicareDoc $^{\circ}$ \\
\hline 26 & 6MWT & 6-Minute Walk Test & WicareDoc $^{\circ}$ \\
\hline 27 & TUG & Timed Up and Go Test & WicareDoc $^{\circ}$ \\
\hline 28 & ATRS & Adductor Tone Rating Scale & WicareDoc $^{\circ}$ \\
\hline 29 & PSFS & Penn Spasm Frequency Scale & Paper $^{\circ}$ \\
\hline 30 & - & Clonus Scale & Paper $^{\circ}$ \\
\hline 31 & BBS & Berg Balance Scale & WicareDoc ${ }^{\circ}$ \\
\hline [32] & FRT & Functional Reach Test & WicareDoc ${ }^{\circ}$ \\
\hline $33, \mathrm{NA}$ & Mini BESTest & Mini Balance Evaluation Systems Test & Paper $^{\circ}$ \\
\hline 34 , NA & - & Tinetti Test & Paper $^{\circ}$ \\
\hline 35 , NA & NRS & Numeric Rating Scale & Paper $^{\circ}$ \\
\hline [36] & GRASSP & $\begin{array}{l}\text { Graded Redefined Assessment of Strength } \\
\text { Sensibility and Prehension }\end{array}$ & Paper $^{+}$ \\
\hline [37] & MMT UE & Manual Muscle Test Upper Extremities & WicareDoc $^{+}$ \\
\hline 38 & - & Hand Dynanometry & Paper $^{+}$ \\
\hline [39] & $\begin{array}{l}\text { ROM Wrist and } \\
\text { Finger }\end{array}$ & Range Of Motion Wrist and Finger & WicareDoc $^{+}$ \\
\hline 40 & & $\begin{array}{l}\text { Sensibility according to Semmes Weinstein } \\
\text { (SPC) }\end{array}$ & Paper $^{+}$ \\
\hline
\end{tabular}


Table 1 (continued)

\begin{tabular}{|c|c|c|c|}
\hline & Abbreviation & Full name & $\begin{array}{l}\text { Documentation place } \\
\text { Profession }\end{array}$ \\
\hline 41 & & Functional State of Sensibility (SPC) & Paper $^{+}$ \\
\hline 42 & & State of Housekeeping (SPC) & Paper $^{+}$ \\
\hline 43, NA & - & Diagnostics Decubitus (SPC) & Paper+ \\
\hline $44, \mathrm{NA}$ & - & $\begin{array}{l}\text { Assessment of Sitting Position in a } \\
\text { Wheelchair according to ICF }\end{array}$ & Paper $^{+}$ \\
\hline 45, NA & COPM & Canadian Occupational Performance Measure & Medfolio $^{+}$ \\
\hline 46, NA & GAS & Goal Attainment Scale & Paper $^{+}$ \\
\hline 47, NA & - & EA OT-Assessment & Paper $^{+}$ \\
\hline 48, NA & PPBT & Purdue Pegboard Test & Paper $^{+}$ \\
\hline 49, NA & NHPT & Nine Hole Peg Test & Paper $^{+}$ \\
\hline 50, NA & AFM & Allensbacher's Fine Motor Skills Test & Paper $^{+}$ \\
\hline 51, NA & ADL & Assessment for Activity of Daily Life (SPC) & Paper $^{+}$ \\
\hline 52 , NA & DASH & $\begin{array}{l}\text { Disabilities of the Arm Shoulder and Hand } \\
\text { questionnaire }\end{array}$ & Paper $^{+}$ \\
\hline 53 & - & Skin Assessment (SPC) & WicareDoc $^{\#}$ \\
\hline 54 & GCS & Glasgow Coma Scale & WicareDoc ${ }^{\#}$ \\
\hline
\end{tabular}

Responsible profession: * Physicians, ${ }^{\circ}$ Physiotherapists, ${ }^{+}$Occupational Therapists, ${ }^{\sharp}$ Nurses (excluded assessments for group comparison). $N A$ never applied assessments

Management Cockpit, 1.5.400.100 (SPARE GmbH, Switzerland), and PACS, 5.0.95154 (Phönix-PACS GmbH, Germany). Assessments were either documented in electronic databases or manually collected in different paper documents.

For the analysis, based on the dataset derived from the second part of the data collection the number of assessments per patient was determined, before it was merged with the first dataset. Ultimately, the data were reversibly pseudonymized. The data are stored in the clinical trial unit of the institute and can be made available on request (clinical.trial. unit@paraplegie.ch).

\section{Statistical analysis}

The patient characteristics (sex, age at admission, length of stay, nature of SCI, completeness of lesion, and the American Spinal Injury Association (ASIA) Impairment Scale (AIS) category at admission and discharge) are presented as numbers and percentages. The $\chi^{2}$ test was carried out to evaluate differences between patient groups. The average, minimum, and maximum number of administrations per person for all instruments was calculated according to the level of injury (paraplegia/tetraplegia) and further stratified according to the completeness of the lesion (complete/incomplete). Assessments suitable for all patients were then compared in terms of the average number of administrations per person according to the level of injury and the level of completeness of the lesion. Monthly categories for assessments were built based on 30-day periods rather than calendar months. The number of administrations per person for every assessment instrument was $0,1,2$, or $\geq 3$. A $p$ value of $\leq 0.05$ was considered to indicate statistical significance, and calculations were performed using Stata (version 13.1).

\section{Results}

\section{Demographic and clinical characteristics of the patients}

A total of 119 patients (83 males: 43 with paraplegia, 65 with traumatic SCI, and 37 with complete lesions) with a mean age of 54 years were included (Table 2). At admission, 37 patients had AIS A; 28, AIS B; 28, AIS C, and 26, AIS D (Table 2). Statistically significant differences were found between the participants with paraplegia and tetraplegia with regard to the length of stay and cause of SCI. More traumatic causes of SCI were observed in tetraplegic patients, whereas more non-traumatic causes were noticed in patients with paraplegia (Table 2). Mean duration from the first diagnosis of SCI to admission at the SPC was 22.79 days $(\min =0$ days, $\max =192$ days), with $76 \%$ of the patients admitted within 1 month, $17 \%$ admitted between 1 and 2 months after onset of SCI, 5\% between 2 and 3 months, and $3 \%$ admitted after more than 3 months. The percentage of patients who stayed for more than 10 months was higher in the tetraplegic than in the paraplegic group (Table 2). 
Table 2 Patient characteristics of patients with spinal cord injury (admission December 2013-December 2014)

\begin{tabular}{|c|c|c|c|}
\hline & $\begin{array}{l}\text { Paraplegia } \\
N=43 n(\%)\end{array}$ & $\begin{array}{l}\text { Tetraplegia } \\
N=76 n(\%)\end{array}$ & $p$ value* \\
\hline \multicolumn{4}{|l|}{ Sex } \\
\hline Male & $30(69.77)$ & $53(69.74)$ & \multirow[t]{2}{*}{1.00} \\
\hline Female & $13(30.23)$ & $23(30.26)$ & \\
\hline \multicolumn{4}{|c|}{ Age at admission (years) } \\
\hline $18-34$ & $11(25.58)$ & $19(25.00)$ & \multirow[t]{5}{*}{0.22} \\
\hline $35-49$ & $7(16.28)$ & $6(7.89)$ & \\
\hline $50-64$ & $10(23.26)$ & $25(32.89)$ & \\
\hline $65-79$ & $9(20.93)$ & $22(28.95)$ & \\
\hline$\geq 80$ & $6(13.95)$ & $4(5.26)$ & \\
\hline \multicolumn{4}{|c|}{ Length of stay (months) } \\
\hline $0-3$ & $8(18.60)$ & $20(26.32)$ & \multirow[t]{5}{*}{$0.02 * *$} \\
\hline $4-6$ & $19(44.19)$ & $18(23.68)$ & \\
\hline $7-9$ & $15(34.88)$ & $22(28.95)$ & \\
\hline $10-12$ & $1(2.33)$ & $14(18.42)$ & \\
\hline$>12$ & $0(0.00)$ & $2(2.63)$ & \\
\hline \multicolumn{4}{|l|}{ Cause of SCI } \\
\hline Traumatic & $18(41.86)$ & $47(61.84)$ & \multirow[t]{2}{*}{$0.04^{* *}$} \\
\hline Non-traumatic & $25(58.14)$ & $29(38.16)$ & \\
\hline \multicolumn{4}{|l|}{ SCI severity } \\
\hline Complete & $11(25.58)$ & $26(34.21)$ & \multirow[t]{2}{*}{0.33} \\
\hline Incomplete & $32(74.42)$ & $50(65.79)$ & \\
\hline \multicolumn{4}{|l|}{ AIS at admission } \\
\hline A & $11(25.58)$ & $26(34.21)$ & \multirow[t]{4}{*}{0.72} \\
\hline $\mathrm{B}$ & $11(25.58)$ & $17(22.37)$ & \\
\hline $\mathrm{C}$ & $12(27.91)$ & $16(21.05)$ & \\
\hline $\mathrm{D}$ & $9(20.93)$ & $17(22.37)$ & \\
\hline \multicolumn{4}{|l|}{ AIS at discharge } \\
\hline A & $11(25.58)$ & $25(32.89)$ & \multirow[t]{4}{*}{0.29} \\
\hline B & $10(23.26)$ & $16(21.05)$ & \\
\hline $\mathrm{C}$ & $12(27.91)$ & $11(14.47)$ & \\
\hline $\mathrm{D}$ & $10(23.26)$ & $24(31.58)$ & \\
\hline
\end{tabular}

AIS American Spinal Injury Association (ASIA) Impairment Scale, $S C I$ spinal cord injury

* $p$ values were calculated based on $\chi^{2}$ test

** Significant at $5 \%$ significance level

\section{Administration of assessment instruments}

The assessment instruments were administered by physicians, neuropsychologists, nurses, PTs, and OTs. Psychologists, nutritional consultants, and speech therapists did not administer standardized assessment instruments at the time.

Of the 54 instruments, 41 were administered (Table 1), and the unused instruments are shown in Table 1. Physicians and neuropsychologists used Medfolio and PACS, whereas PTs, OTs, and nurses used WicareDoc. The only interdisciplinary instrument used was the SCIM III, which was administered by nurses, OTs, and PTs and documented in Medfolio.

Across all patients, SCIM III was the most commonly administered instrument (mean number of assessments per patient $=7.7$ ) $($ Table 3 ). The other frequently used instruments were skin assessment (mean $=3.6$ ) by nurses, MMT (mean for the lower extremities $(\mathrm{LE})=3.2$, mean for the upper extremities $(\mathrm{UE})=2.5$ ) by PTs and OTs, radiography of the spine (mean $=2.3$ ) and magnetic resonance imaging (MRI) of the spine (mean =1.2) by physicians, and ROM (mean for $\mathrm{LE}=2.1$, mean for $\mathrm{UE}=1.5$, mean for the wrist and finger $=1.1$ ) by PTs. The AIS was on average used 1.9 times by physicians. The 10 most infrequently used instruments are shown in Table 3. With the exception of Phrenicus-ENG and Functional State of Sensibility in upper extremity, all the tetraplegia-specific instruments were also used in some patients with paraplegia (Table 3).

The number of AIS measurements was higher in patients with paraplegia than in those with tetraplegia, whereas osteoporosis diagnostics was more frequent in those with tetraplegia (Table 4). The frequency of the other assessments did not significantly differ between paraplegic and tetraplegic patients. However, urodynamics studies, spine radiography, computed tomography (CT) of the spine, the Ashworth Scale (AS), the Adductor Tone Rating Scale (ATRS), and skin assessments were more frequently performed in patients with complete lesions than in patients with incomplete lesions (Table 4). In contrast, MMT of the LE, ROM of the LE, and the 6-Minute Walk Test (6MWT) were administered more frequently in patients with incomplete lesions (Table 4). The frequency of the other assessments did not significantly differ between patients with complete lesions and those with incomplete lesions.

Within the complete and incomplete lesion groups the frequency of osteoporosis diagnostics, Time Up and Go (TUG), 6MWT, ATRS, Penn Spasm Frequency Scale (PSFS), Berg Balance Scale (BBS), and State of Housekeeping differed between tetraplegic and paraplegic patients (supplementary file). Among the patients with incomplete lesions, the Walking Index for Spinal Cord Injury (WISCI) was used twice as often in paraplegics than in tetraplegics $(p=0.05)$ (supplementary file).

\section{Discussion}

A total of 41 different assessments were administered during the first rehabilitation intervention after a newly acquired SCI. On average, 10 assessments were administered more than once per patient and 6 were administered more than twice. The most frequently used assessments were SCIM III, MMT LE, skin assessment, spine radiography, MMT of UE, ROM (LE, UE, wrist, and 
Table 3 Average, minimum, and maximum administration of assessments in patients with SCI during first rehabilitation, $n=119$

\begin{tabular}{|c|c|c|c|c|c|}
\hline & \multirow{2}{*}{$\begin{array}{l}\text { All } \\
\text { Mean } \\
(\min ; \max )\end{array}$} & \multicolumn{2}{|l|}{ Paraplegia } & \multicolumn{2}{|l|}{ Tetraplegia } \\
\hline & & $\begin{array}{l}\text { Complete } \\
\text { Mean (min;max) }\end{array}$ & $\begin{array}{l}\text { Incomplete } \\
\text { Mean (min;max) }\end{array}$ & $\begin{array}{l}\text { Complete } \\
\text { Mean (min;max) }\end{array}$ & $\begin{array}{l}\text { Incomplete } \\
\text { Mean (min;max) }\end{array}$ \\
\hline \multicolumn{6}{|l|}{ Physician } \\
\hline $\mathrm{AIS}^{\circ}$ & $1.85(0 ; 3)$ & $1.91(1 ; 2)$ & $1.97(0 ; 3)$ & $1.77(1 ; 2)$ & $1.80(0 ; 2)$ \\
\hline MMI & $0.51(0 ; 1)$ & $0.64(0 ; 1)$ & $0.53(0 ; 1)$ & $0.54(0 ; 1)$ & $0.46(0 ; 1)$ \\
\hline Urodynamics & $0.92(0 ; 3)$ & $1.18(0 ; 2)$ & $0.84(0 ; 2)$ & $1.12(0 ; 3)$ & $0.82(0 ; 3)$ \\
\hline X-ray Spine ${ }^{\circ}$ & $2.27(0 ; 10)$ & $4.09(0 ; 10)$ & $1.84(0 ; 7)$ & $2.35(0 ; 6)$ & $2.10(0 ; 7)$ \\
\hline CT Spine & $0.59(0 ; 5)$ & $0.82(0 ; 3)$ & $0.59(0 ; 2)$ & $0.73(0 ; 4)$ & $0.46(0 ; 5)$ \\
\hline MRI Spine ${ }^{\circ}$ & $1.23(0 ; 8)$ & $1.18(0 ; 4)$ & $1.47(0 ; 8)$ & $1.15(0 ; 4)$ & $1.12(0 ; 3)$ \\
\hline Osteoporosis Diagnostics & $0.11(0 ; 1)$ & $0.00(0 ; 0)$ & $0.03(0 ; 1)$ & $0.04(0 ; 1)$ & $0.22(0 ; 1)$ \\
\hline PFT & $0.53(0 ; 3)$ & $0.36(0 ; 1)$ & $0.50(0 ; 3)$ & $0.42(0 ; 2)$ & $0.64(0 ; 2)$ \\
\hline Performance Test & $0.06(0 ; 2)$ & $0.09(0 ; 1)$ & $0.06(0 ; 2)$ & $0.04(0 ; 1)$ & $0.06(0 ; 2)$ \\
\hline $\mathrm{SEP}+$ ENG Tibialis & $0.93(0 ; 3)$ & $0.91(0 ; 1)$ & $0.91(0 ; 2)$ & $0.92(0 ; 2)$ & $0.96(0 ; 3)$ \\
\hline PAP & $0.35(0 ; 1)$ & $0.36(0 ; 1)$ & $0.34(0 ; 1)$ & $0.35(0 ; 1)$ & $0.36(0 ; 1)$ \\
\hline SEP + ENG Ulnaris & $0.45(0 ; 2)$ & $0.00(0 ; 0)$ & $0.13(0 ; 1)$ & $0.73(0 ; 2)$ & $0.60(0 ; 2)$ \\
\hline Phrenicus-ENG & $0.09(0 ; 2)$ & $0.00(0 ; 0)$ & $0.00(0 ; 0)$ & $0.27(0 ; 2)$ & $0.08(0 ; 2)$ \\
\hline TTT & $0.23(0 ; 1)$ & $0.09(0 ; 1)$ & $0.03(0 ; 1)$ & $0.50(0 ; 1)$ & $0.24(0 ; 1)$ \\
\hline \multicolumn{6}{|l|}{ Physiotherapist } \\
\hline MMT LE ${ }^{\circ}$ & $3.24(0 ; 9)$ & $2.64(0 ; 9)$ & $3.84(0 ; 8)$ & $1.58(0 ; 6)$ & $3.84(0 ; 8)$ \\
\hline $\mathrm{ROM} \mathrm{UE}^{\circ}$ & $1.54(0 ; 5)$ & $0.82(0 ; 3)$ & $1.09(0 ; 4)$ & $2.04(0 ; 5)$ & $1.72(0 ; 5)$ \\
\hline $\mathrm{ROM} \mathrm{LE}^{\circ}$ & $2.11(0 ; 4)$ & $2.09(0 ; 4)$ & $2.25(0 ; 4)$ & $2.12(0 ; 4)$ & $2.02(0 ; 3)$ \\
\hline WISCI II & $0.67(0 ; 5)$ & $0.82(0 ; 3)$ & $0.66(0 ; 4)$ & $0.42(0 ; 3)$ & $0.78(0 ; 5)$ \\
\hline Diagnostics Breathing Therapy* & $0.03(0 ; 2)$ & $0.00(0 ; 0)$ & $0.03(0 ; 1)$ & $0.08(0 ; 2)$ & $0.00(0 ; 0)$ \\
\hline AMW & $0.46(0 ; 5)$ & $0.82(0 ; 4)$ & $0.66(0 ; 3)$ & $0.42(0 ; 3)$ & $0.28(0 ; 5)$ \\
\hline Diagnostics Shoulder Examination* & $0.03(0 ; 1)$ & $0.09(0 ; 1)$ & $0.00(0 ; 0)$ & $0.04(0 ; 1)$ & $0.02(0 ; 1)$ \\
\hline WUSPI & $0.24(0 ; 2)$ & $0.18(0 ; 1)$ & $0.31(0 ; 2)$ & $0.27(0 ; 2)$ & $0.20(0 ; 2)$ \\
\hline AS & $0.07(0 ; 2)$ & $0.09(0 ; 1)$ & $0.03(0 ; 1)$ & $0.23(0 ; 2)$ & $0.00(0 ; 0)$ \\
\hline 6MWT & $0.50(0 ; 6)$ & $0.00(0 ; 0)$ & $0.63(0 ; 6)$ & $0.00(0 ; 0)$ & $0.78(0 ; 6)$ \\
\hline TUG & $0.08(0 ; 3)$ & $0.00(0 ; 0)$ & $0.09(0 ; 2)$ & $0.00(0 ; 0)$ & $0.12(0 ; 3)$ \\
\hline ATRS* & $0.04(0 ; 2)$ & $0.00(0 ; 0)$ & $0.00(0 ; 0)$ & $0.19(0 ; 2)$ & $0.00(0 ; 0)$ \\
\hline PSFS* & $0.01(0 ; 1)$ & $0.00(0 ; 0)$ & $0.00(0 ; 0)$ & $0.04(0 ; 1)$ & $0.00(0 ; 0)$ \\
\hline Clonus Scale* & $0.03(0 ; 1)$ & $0.00(0 ; 0)$ & $0.00(0 ; 0)$ & $0.08(0 ; 1)$ & $0.02(0 ; 1)$ \\
\hline BBS* & $0.02(0 ; 1)$ & $0.00(0 ; 0)$ & $0.00(0 ; 0)$ & $0.00(0 ; 0)$ & $0.04(0 ; 1)$ \\
\hline FRT* & $0.06(0 ; 2)$ & $0.00(0 ; 0)$ & $0.06(0 ; 2)$ & $0.00(0 ; 0)$ & $0.10(0 ; 2)$ \\
\hline \multicolumn{6}{|l|}{ Occupational Therapist } \\
\hline GRASSP & $0.51(0 ; 4)$ & $0.00(0 ; 0)$ & $0.06(0 ; 1)$ & $0.73(0 ; 4)$ & $0.80(0 ; 4)$ \\
\hline MMT UE & $2.47(0 ; 11)$ & $0.18(0 ; 2)$ & $0.47(0 ; 4)$ & $3.73(0 ; 11)$ & $3.60(0 ; 11)$ \\
\hline Hand Dynanometry & $0.60(0 ; 7)$ & $0.00(0 ; 0)$ & $0.31(0 ; 3)$ & $0.12(0 ; 3)$ & $1.16(0 ; 7)$ \\
\hline ROM Wrist and Finger ${ }^{\circ}$ & $1.13(0 ; 5)$ & $0.00(0 ; 0)$ & $0.13(0 ; 3)$ & $2.15(0 ; 5)$ & $1.50(0 ; 4)$ \\
\hline Sensibility (S. Weinstein) & $0.15(0 ; 3)$ & $0.00(0 ; 0)$ & $0.06(0 ; 1)$ & $0.00(0 ; 0)$ & $0.32(0 ; 3)$ \\
\hline Functional State of Sensibility* & $0.01(0 ; 1)$ & $0.00(0 ; 0)$ & $0.00(0 ; 0)$ & $0.00(0 ; 0)$ & $0.02(0 ; 1)$ \\
\hline State of Housekeeping* & $0.01(0 ; 1)$ & $0.00(0 ; 0)$ & $0.00(0 ; 0)$ & $0.04(0 ; 1)$ & $0.00(0 ; 0)$ \\
\hline \multicolumn{6}{|l|}{ Nursing } \\
\hline Skin Assessment ${ }^{\circ}$ & $3.59(0 ; 37)$ & $3.91(0 ; 16)$ & $2.16(0 ; 13)$ & $6.27(0 ; 37)$ & $3.04(0 ; 34)$ \\
\hline GCS* & $0.04(0 ; 2)$ & $0.00(0 ; 0)$ & $0.06(0 ; 1)$ & $0.04(0 ; 1)$ & $0.04(0 ; 2)$ \\
\hline \multicolumn{6}{|l|}{ Mixed } \\
\hline SCIM III $^{\circ}$ & $7.71(1 ; 16)$ & $8.09(2 ; 12)$ & $6.72(2 ; 10)$ & $9.27(2 ; 16)$ & $7.46(1 ; 15)$ \\
\hline
\end{tabular}


Table 3 (continued)

\begin{tabular}{lllll} 
All & Paraplegia & & Tetraplegia & \\
\cline { 2 - 3 } $\begin{array}{l}\text { Mean } \\
(\min ; \max )\end{array}$ & $\begin{array}{l}\text { Complete } \\
\text { Mean (min;max })\end{array}$ & $\begin{array}{l}\text { Incomplete } \\
\text { Mean (min;max })\end{array}$ & $\begin{array}{l}\text { Complete } \\
\text { Mean }(m i n ; m a x)\end{array}$ & $\begin{array}{l}\text { Incomplete } \\
\text { Mean (min;max) }\end{array}$ \\
$0.27(0 ; 2)$ & $0.27(0 ; 1)$ & $0.31(0 ; 2)$ & $0.31(0 ; 1)$ & $0.22(0 ; 2)$ \\
\hline
\end{tabular}

CI spinal cord injury, SPC Swiss Paraplegic Center, AIS American Spinal Injury Association (ASIA) Impairment Scale, MMI Multimorbidity Index, CT Computed Tomography, MRI Magnetic Resonance Imaging, PFT Pulmonary Function Test, SEP + ENG Sensible Evoked Potentials + Elektroneurografie, PAP Peripheral Activated Potentials, TTT Tilt Table Test, MMT Manual Muscle Test, LE Lower Extremities, ROM Range Of Motion, UE Upper Extremities, WISCI Walking Index for Spinal Cord Injury, AMW Activity Test for Mobility in Wheelchair, WUSPI Wheelchair User's Shoulder Pain Index, AS Ashworth Scale, 6MWT 6-Minute Walk Test, TUG Timed Up and Go Test, ATRS Adductor Tone Rating Scale, PSFS Penn Spasm Frequency Scale, BBS Berg Balance Scale, FRT Functional Reach Test, GRASSP Graded Redefined Assessment of Strength Sensibility and Prehension, GCS Glasgow Coma Scale, SCIM Spinal Cord Independence Measure ${ }^{\circ}$ Most frequent used assessments

* Most infrequent used assessments

finger), AIS, MRI of the spine, and urodynamics examination.

The highest variation in the number of assessments per patient was observed between patients with complete and incomplete lesions, and the least was observed between patients with paraplegia and tetraplegia.

\section{Frequency of administration of the assessments}

In order to measure the changes that occur during rehabilitation, assessments need to be performed at least twice, ideally at the beginning and at the end of an intervention $[10,11,26]$. In this study, only six assessments that were administered by four professionals satisfied this criterion, which are SCIM III, AIS, spinal radiography, MRI, ROM, and MMT, highly recommended by the ISCOS consensus conference [14]. Based on the national and international recommendations and actual practices, these assessments can be considered as valuable and established standards of outcome measurements for all SCI patient groups. The monthly frequency of use of SCIM III further indicates the importance of this assessment as part of clinical management strategies; moreover, it is accepted as an international standard $[14,27,28]$ and is recommended by the National Quality Association of Switzerland [24]. To ensure that the repeated assessments are of high quality, integrated monitoring processes are needed. In the absence of any monitoring mechanism, and based on clinical decisions by individual practitioners, AIS and MMT were repeated more than twice on average, but they were not consistently used in every patient. The frequency and consistency of these assessments are not in keeping with those of standardized outcome measurements or with the national reporting standards [26]. Once a standard is in place, an explicit support or recall system and performance controls should be implemented [1] to increase the quality of the data collection. Further, to keep the clinical burden as low as possible, the assessments included in the standard assessment toolkit should be chosen wisely $[1,3]$.

\section{Assessments used in the first rehabilitation after $\mathrm{SCI}$}

Physicians and therapists use assessments to measure clinical changes [1] and choose the assessments based on the expected outcomes and rehabilitation goals of patients. A relevant prerequisite for clinical confidence is that the psychometrical test considers the validity and reproducibility of selected assessments as described in the SCIRE project [15] and the Common Data Elements [19]. Characteristics of patients with paraplegia or tetraplegia, and characteristics of patients with complete or incomplete lesions differ substantially in each group [15, 29]. Accordingly, the assessments used are specific to each patient group: for example, GRASSP is used more often in tetraplegic patients; WISCI II and 6MWT are used more frequently in patients with walking abilities; and MMT is used more commonly in SCI patients with incomplete lesions. Therefore, a standardized assessment toolkit should be supplemented with specific assessments for each patient subgroup to measure clinically relevant changes, to reflect the differences in the functioning of patients, and to further increase the motivation of therapists, physicians, and patients [1]. In summary, the recommendations should include some assessments for patients with SCI in general and some for relevant functional subgroups or in response to specific clinical questions. In this way, the content of different assessment kits is part of the nationally and internationally accepted standards as well as allows health professionals to choose additional assessments to demonstrate specific and individual outcomes of rehabilitation. Moreover, the electronic medical records should use a format that can be adapted to each individual as well as standardized formats for mandatory data collection [4]. 
Table 4 Average of assessments per patient during first rehabilitation, by level of injury (paraplegia vs. petraplegia) and complete vs. incomplete lesion

\begin{tabular}{|c|c|c|c|c|c|c|}
\hline & $\begin{array}{l}\text { Paraplegia } \\
\text { Mean }\end{array}$ & $\begin{array}{l}\text { Tetraplegia } \\
\text { Mean }\end{array}$ & $p$ value* & $\begin{array}{l}\text { Complete } \\
\text { Mean }\end{array}$ & $\begin{array}{l}\text { Incomplete } \\
\text { Mean }\end{array}$ & $p$ value* \\
\hline \multicolumn{7}{|l|}{ Physician } \\
\hline AIS & 1.95 & 1.79 & $0.04 * *$ & 1.81 & 1.87 & 0.37 \\
\hline MMI & 0.56 & 0.49 & 0.46 & 0.57 & 0.49 & 0.42 \\
\hline Urodynamics & 0.93 & 0.92 & 0.24 & 1.14 & 0.83 & $0.02 * *$ \\
\hline X-ray Spine & 2.42 & 2.18 & 0.10 & 2.86 & 2.00 & $0.03 * *$ \\
\hline CT Spine & 0.65 & 0.55 & 0.53 & 0.76 & 0.51 & $0.03 * *$ \\
\hline MRI Spine & 1.40 & 1.13 & 0.13 & 1.16 & 1.26 & 0.98 \\
\hline \multicolumn{7}{|l|}{ Diagnostics } \\
\hline PFT & 0.47 & 0.57 & 0.19 & 0.41 & 0.59 & 0.16 \\
\hline Performance Test & 0.07 & 0.05 & 0.92 & 0.05 & 0.06 & 0.26 \\
\hline SEP + ENG Tibialis & 0.91 & 0.95 & 0.89 & 0.92 & 0.94 & 0.88 \\
\hline PAP & 0.35 & 0.36 & 0.94 & 0.35 & 0.35 & 0.98 \\
\hline \multicolumn{7}{|l|}{ Physical Therapist } \\
\hline MMT LE & 3.53 & 3.07 & 0.27 & 1.89 & 3.84 & $0.00 * *$ \\
\hline ROM LE & 2.21 & 2.05 & 0.37 & 2.11 & 2.11 & $0.01 * *$ \\
\hline WISCI II & 0.70 & 0.66 & 0.98 & 0.54 & 0.73 & 0.33 \\
\hline AS & 0.05 & 0.08 & 0.48 & 0.19 & 0.01 & $0.02 * *$ \\
\hline $6 \mathrm{MWT}$ & 0.47 & 0.51 & 0.36 & 0.00 & 0.72 & $0.00 * *$ \\
\hline TUG & 0.07 & 0.08 & 0.47 & 0.00 & 0.11 & 0.42 \\
\hline ATRS & 0.00 & 0.07 & 0.31 & 0.14 & 0.00 & $0.01 * *$ \\
\hline PSFS & 0.00 & 0.01 & 0.45 & 0.03 & 0.00 & 0.14 \\
\hline Clonus Scale & 0.00 & 0.04 & 0.19 & 0.05 & 0.01 & 0.18 \\
\hline BBS & 0.00 & 0.03 & 0.28 & 0.00 & 0.02 & 0.34 \\
\hline \multicolumn{7}{|l|}{ Occupational Therapist } \\
\hline State of Housekeeping & 0.00 & 0.01 & 0.45 & 0.03 & 0.00 & 0.14 \\
\hline \multicolumn{7}{|l|}{ Nursing } \\
\hline Skin Assessment & 2.60 & 4.14 & 0.59 & 5.57 & 2.70 & $0.02 * *$ \\
\hline GCS & 0.05 & 0.04 & 0.41 & 0.03 & 0.05 & 0.79 \\
\hline \multicolumn{7}{|l|}{ Mixed } \\
\hline SCIM III & 7.07 & 8.08 & 0.64 & 8.92 & 7.17 & 0.57 \\
\hline \multicolumn{7}{|l|}{ Neuropsychology } \\
\hline $\begin{array}{l}\text { Neuropsychological } \\
\text { Examination }\end{array}$ & 0.30 & 0.25 & 0.84 & 0.30 & 0.26 & 0.38 \\
\hline
\end{tabular}

AIS American Spinal Injury Association (ASIA) Impairment Scale, MMI Multimorbidity Index, $C T$ Computed Tomography, MRI Magnetic Resonance Imaging, PFT Pulmonary Function Test, SEP + ENG Sensible Evoked Potentials + Elektroneurografie, PAP Peripheral Activated Potentials, MMT Manual Muscle Test, LE Lower Extremities, ROM Range Of Motion, WISCI Walking Index for Spinal Cord Injury, $A S$ Ashworth Scale, 6MWT 6-Minute Walk Test, TUG Timed Up and Go Test, ATRS Adductor Tone Rating Scale, PSFS Penn Spasm Frequency Scale, BBS Berg Balance Scale, GCS Glasgow Coma Scale, SCIM Spinal Cord Independence Measure

* $p$ values were calculated based on $\chi^{2}$ test, frequencies of assessment application were divided into the categories $0,1,2$, and $\geq 3$

** Significant at $5 \%$ significance level
From the perspective of the ICF, the often-administered assessments cover structure, functioning, and activity. An example of structure assessment is the skin assessment, which is the second most commonly used assessment. The number of skin assessments underlines the clinical importance of skin changes, which often occur as complications during the first rehabilitation after SCI [30]. According to international recommendations, the AIS is considered as an 
indicator of neurological changes [14, 27], and clinically relevant assessments, such as MMT of UE/LE, ROM of UE/LE/wrist and finger, spinal radiography and spinal MRI, cover structure, and functioning. These assessments are also included in other countries recommendations such as Canada [3]. However, we found that certain nationally and internationally recommended assessments were not covered, such as assessments that evaluate pain and autonomic dysfunction [31, 32], and outcome measures for colon and rectal function, sexual function, depression, and quality of life $[17,18]$. In addition, no psychometrically tested assessment instrument for participation was administered, but the general nationally accepted criteria for discharge or admission to an institute are documented and could be used for management and outcome evaluation. With regard to the ICF core set for SCI, assessments evaluating energy, emotion, pain, and employment are also missing $[5,26]$. Therefore, to cover the recommended domains and in consideration of international reporting requirements, specific additional assessments should be implemented in clinical practice [15]. A sustainable assessment toolkit should be created based on daily practices and the recommendations of international specialists. After the administered assessments are described, the selection of additionally required assessments must be followed by their implementation and the engagement of stakeholders to achieve the assessment standards as described in the SCIRE guidelines [15]. Like guidelines, an assessment toolkit also needs regular updates to include the newest evidence from psychometrically tested assessments.

The main limitation of this study was that the information was collected manually, which means that some assessments could have been missed. A documenting system in a rehabilitation setting and a central overview of all administered assessments would be recommended. The unequal distribution of the 119 study participants in the respective groups was representative of the Swiss SCI population [33], but the sample size was too small for meaningful descriptive statistical analyses of some subgroups. Therefore, some of the significant group differences might be attributable to subgroup size and must be interpreted with caution.

\section{Conclusion}

With respect to the quality of rehabilitation management, the observed assessments could be useful for the development of a standardized assessment toolkit that includes all the required assessments for all patient groups at the beginning of an intervention and at the end. An administrative control process as in the SCIM administration can ensure the successful performance of such an assessment toolkit. However, it was observed that assessments of motor function, mobility and self-care are well established, while others concerning autonomic nerve system, mental health, participation, and environment are still missing.

This study reveals that for different patient subgroups, additional assessments were administered in addition to the general assessments. That is, clinicians' selected additional specific clinically indicated assessments based on the needs of individual patients and the goal-setting process. The choice of assessments was based on clinical or scientific reasoning. To achieve a relevant and valid standard, the selected assessments were psychometrically tested. For global comparison and standardized reporting, the different domains from a worldwide functioning standard have not yet been sufficiently covered. Further research on the implementation of outcome measures in clinical management is recommended.

Acknowledgements We thank the interdisciplinary team and the diverse health professionals for their assistance with the data collection. We also thank Daniel Apap for his precious comments and the English revision.

\section{Compliance with ethical standards}

Conflict of interest The authors declare that they have no conflict of interest.

\section{References}

1. Turner-Stokes L, Williams H, Sephton K, Rose H, Harris S, Thu A. Engaging the hearts and minds of clinicians in outcome measurement-the UK Rehabilitation Outcomes Collaborative approach. Disabilility Rehabil. 2012;34:1871-79.

2. Stucki G, Zampolini M, Juocevicius A, Negrini S, Christodoulou $\mathrm{N}$. Practice, science and governance in interaction: European effort for the system-wide implementation of the International Classification of Functioning, Disability and Health (ICF) in Physical and Rehabilitation Medicine. Eur J Phys Rehabil Med. 2017;53:299-307.

3. Chan CWL, Miller WC, Querée M, Noonan VK, Wolfe DL. The development of an outcome measures toolkit for spinal cord injury rehabilitation. Can J Occup Ther. 2017;84:119-29.

4. Prodinger B, Ballert CS, Brach M, Brinkhof MWG, Cieza A, Hug $\mathrm{K}$, et al. Toward standardized reporting for a cohort study on functioning: The Swiss Spinal Cord Injury Cohort Study. J Rehabil Med. 2016;48:189-96.

5. Prodinger B, Cieza A, Oberhauser C, Bickenbach J, Üstün TB, Chatterji $\mathrm{S}$, et al. Toward the International Classification of Functioning, Disability and Health (ICF) Rehabilitation Set: a minimal generic set of domains for rehabilitation as a health strategy. Archiv Phys Med Rehabil. 2016;97:875-84.

6. Grimby G, Melvin J, Stucki G. The ICF: a unifying model for the conceptualization, organization and development of human functioning and rehabilitation research. J Rehabil Med. 2007;39:273-344.

7. Ballert CS, Stucki G, Biering-Sørensen F, Cieza A. Towards the development of clinical measures for spinal cord injury based on the International Classification of Functioning, Disability and 
Health with Rasch analyses. Arch Phys Med Rehabil. 2014;95:1685-94.

8. Fekete C, Boldt C, Post M, Eriks-Hoogland I, Cieza A, Stucki G. How to measure what matters: development and application of guiding principles to select measurement instruments in an epidemiologic study on functioning. Am J Phys Med Rehabil. 2011;90:S29-38.

9. Chhabra HS. ISCOS textbook on comprehensive management of spinal cord injuries; 2015. ISBN-13: 978-93 (Lippincott Williams \& Wilkins, Philadelphia, USA).

10. van Hedel HJ. Improvement in function after spinal cord injury: the black-box entitled rehabilitation. Swiss Med Wkly. 2012;142: w13673.

11. Steiner WA, Ryser L, Huber E, Uebelhart D, Aeschlimann A, Stucki G. Use of the ICF model as a clinical problem-solving tool in physical therapy and rehabilitation medicine. Phys Ther. 2002;82:1098-107.

12. Anderson K, Aito S, Atkins M, Biering-Sørensen F, Charlifue S, Curt A, et al. Functional recovery measures for spinal cord injury: an evidence-based review for clinical practice and research: report of the national institute on disability and rehabilitation research spinal cord injury measures meeting. J Spinal Cord Med. 2008;31:133.

13. Dorjbal D, Cieza A, Gmünder HP, Scheel-Sailer A, Stucki G, Üstün TB, et al. Strengthening quality of care through standardized reporting based on the World Health Organization's reference classifications. Int J Qual Health Care. 2016;28:626-33.

14. Alexander MS, Anderson KD, Biering-Sorensen F, Blight AR, Brannon R, Bryce TN, et al. Outcome measures in spinal cord injury: recent assessments and recommendations for future directions. Spinal Cord. 2009;47:582-91.

15. SCIRE. Spinal Cord Rehabilitation Evidence. Vancouver, BC: SCIRE Project/Monkey Hill Health Communications. 2016. [cited 2012 06.01.2017]. http://www.scireproject.com.

16. Biering-Sorensen F, Alai S, Anderson K, Charlifue S, Chen Y, DeVivo M, et al. Common data elements for spinal cord injury clinical research: a National Institute for Neurological Disorders and Stroke project. Spinal Cord. 2015;53:265-77.

17. Biering-Sørensen F, Charlifue S, DeVivo MJ, Grinnon ST, Kleitman N, Lu Y, et al. Using the spinal cord injury common data elements. Top Spinal Cord Inj Rehabil. 2012;18:23-27.

18. Post MW, Kirchberger I, Scheuringer M, Wollaars MM, Geyh S. Outcome parameters in spinal cord injury research: a systematic review using the International Classification of Functioning, Disability and Health (ICF) as a reference. Spinal Cord. 2010;48:522-8.

19. Biering-Sørensen F, Alexander M, Burns S, Charlifue S, DeVivo $\mathrm{M}$, Dietz V, et al. Recommendations for translation and reliability testing of international spinal cord injury data sets. Spinal Cord. 2011;49:357-60.
20. Post MW, Brinkhof MW, von Elm E, Boldt C, Brach M, Fekete $\mathrm{C}$, et al. Design of the swiss spinal cord injury cohort study. Am J Phys Med Rehabil. 2011;90:S5-16.

21. Brinkhof MWG, Fekete C, Chamberlain JD, Post MW, Gemperli A. Swiss national community survey on functioning after spinal cord injury: Protocol, characteristics of participants and determinants of non-response. J Rehabil Med. 2016;48:120-30.

22. SwiSCI. Swiss Spinal Cord Injury Cohort Study-SwiSCI, 2017. [cited 2017 14.02.2017]. https://www.swisci.ch/de/.

23. EMSCI. European Multicenter Study about Spinal Cord Injury, 2017. [cited 2017 14.02.2017]. http://emsci.org/

24. ANQ. Nationaler Verein für Qualitätsentwicklung in Spitälern und Kliniken 2017. [cited 2017 14.02.2017]. http://www.anq.ch/de/ rehabilitation/messergebnisse.

25. Organization WH. ICD-10: International statistical classification of diseases and health-related problems. Geneva: WHO; 1992.

26. Prodinger BS-SA, Escorpizo R, Stucki G. UEMS PRM ICF Workshop moderators and rapporteurs. European initiative for the application of the International Classification of Functioning, Disability and Health: development of clinical assessment schedules for specified rehabilitation services. Eur J Phys Rehabil Med. 2017;53:319-32.

27. Hadley MN, Walters BC, Aarabi B, Dhall SS, Gelb DE, Hurlbert $\mathrm{RJ}$, et al. Clinical assessment following acute cervical spinal cord injury. Neurosurgery. 2013;72:40-53.

28. Itzkovich M, Gelernter I, Biering-Sorensen F, Weeks C, Laramee M, Craven B, et al. The Spinal Cord Independence Measure (SCIM) version III: reliability and validity in a Multi-Center International Study. Disabil Rehabil. 2007;29:1926-33.

29. Whiteneck G, Gassaway J, Dijkers MP, Heinemann AW, Kreider SED. Relationship of patient characteristics and rehabilitation services to outcomes following spinal cord injury: the SCIRehab Project. J Spinal Cord Med. 2012;35:484-502.

30. Scheel-Sailer A, Wyss A, Boldt C, Post MW, Lay V. Prevalence, location, grade of pressure ulcers and association with specific patient characteristics in adult spinal cord injury patients during the hospital stay: a prospective cohort study. Spinal Cord. 2013;51:828-33.

31. Karlsson AK, Krassioukov A, Alexander MS, Donovan W, Biering-Sorensen F. International Spinal Cord Injury Skin and Thermoregulation Function Basic Data Set. Spinal Cord. 2012;50:512-16.

32. Krassioukov A. Autonomic function following cervical spinal cord injury. Respir Physiol Neurobiol. 2009;169:157-64.

33. Fekete C, Segerer W, Gemperli A, Brinkhof MW. Participation rates, response bias and response behaviours in the community survey of the Swiss Spinal Cord Injury Cohort Study (SwiSCI). BMC Med Res Methodol. 2015;15:80. 